\title{
Identification of Wound Healing/Regeneration Quantitative Trait Loci (QTL) at Multiple Time Points that Explain Seventy Percent of Variance in (MRL/Mp] and S]L/]) Mice $F_{2}$ Population
}

\author{
Godfred L. Masinde, Xinmin Li, Weikuan Gu, Heather Davidson, \\ Subburaman Mohan, and David J. Baylink ${ }^{1}$ \\ Molecular Genetics Division, Musculoskeletal Disease Center, J.L. Pettis Veterans Administration Medical Center and Loma \\ Linda University, Loma Linda, California 92357, USA
}

\begin{abstract}
Studies on genetic mechanisms of wound healing in mammals are very few, although injury is a leading cause of the global burden of disease. In this study, we performed a high-density, genome-wide scan using 633 $(\mathrm{MRL} / \mathrm{MP}] \times \mathrm{S}$ ]L/J) $\mathrm{F}_{2}$ intercross at multiple time points (days 15, 21, and 25) to identify quantitative trait loci (QTL) involved in wound healing/regeneration. The hypothesis of the study was that QTL and unique epistatic interactions are involved at each time point to promote wound healing/regeneration. Ten QTL were identified from chromosomes 1, 4, 6, 7, 9, and 13. Of the 10 QTL, eight from chromosomes 1, 4, 6, and 9 were novel as compared to QTL identified in the McBrearty et al. (1998) study. The 10 QTL altogether explained $70 \%$ of variance in $\mathrm{F}_{2}$ mice. The same QTL were identified at each time point, with simple linear correlation between days 15,21 , and 25 , showing very high significant relationships $(R>0.92, P<0.0001)$. Unique epistatic interactions were identified at each time point except those from chromosomes 4, 6, 9, and 13 that were found at all three time points, showing that some loci are involved at all the three time points of wound healing (days 15,21 , and 25). Therefore, loci-to-loci interactions may play a major role in wound healing. Information from these studies may help in the identification of genes that could be involved in wound healing/regeneration.
\end{abstract}

Injury is a leading cause of the global burden of disease that occurs in the battlefield for army personnel and as accidents in civilian populations. It is estimated to cost healthcare providers in excess of $\$ 500$ billion per year in the United States alone to treat injuries (Satcher 2000). Therefore, there is an urgent need to develop effective strategies to prevent injuries and promote wound healing after injuries. However, poor understanding of molecular mechanisms underlying fast wound healing/regeneration process has impeded therapeutic treatment of tissue injury.

The primary goal of wound treatment is rapid wound closure with minimal scar formation, which is important for cosmetic appearance (Goss 1992; Martin 1997; Singer and Clark 1999). Wound healing has been accelerated by use of certain proteins like cod liver oil ointment, vitamin A, and deoxyribonucleosides (Shan et al. 1995; Chen et al. 1999; Terkelsen et al. 2000). Animal models have been developed to study mechanisms of wound healing in normal or impaired states (Rothe and Falanga 1992). Although molecular and cell biology studies have explained some of the biological processes that could be involved in wound repair (Rothe and Falanga 1992; Singer et al. 1999), we still know very little about wound healing, as it is a complex process involving

\section{'Corresponding author.}

E-MAIL Baylid@lom.med.va.gov; FAX (909) 796-1680.

Article and publication are at http://www.genome.org/cgi/doi/10.1101/ gr.203701. many genes (Rothe and Falanga 1992; Heber-Katz 1999; Kunimoto 1999; Trengove et al. 2000).

A recent study in our laboratory (Li et al. 2001b) and an earlier study by Clark et al. (1998) indicated that the MRL/ MpJ-Fas $^{\text {lpr }}$ (MRL-F) strain of mice could completely heal an ear-punched hole $(2 \mathrm{~mm}$ in diameter) within $30 \mathrm{~d}$ with no scar tissue. In contrast, the C57BL/6 strain of mice healed only $40 \%$ and SJL $/ \mathrm{J}<25 \%$ of the original hole with scar tissue at the same length of time. To date, McBrearty et al. (1998) have demonstrated that rapid wound healing in MRL-F mice is a genetically controlled quantitative trait. The McBrearty et al. (1998) study used MRL-F and C57BL/6, $F_{2}$ intercross at one time point, which resulted in the identification of five quantitative trait loci (QTL) explaining unknown percentage of variance in $\mathrm{F}_{2}$ mice.

This pioneer study (McBrearty et al. 1998) has demonstrated that MRL mouse is an ideal model to elucidate the molecular mechanisms that underlie wound-repair/ regeneration in mammals. To further identify genetic mechanisms controlling wound healing, we used $F_{2}$ population from progenitor strains that have different genetic origin (MRL/MpJ and SJL/J). The objectives of this study were to map fast-healer genes using two genetically extreme progenitor strains (MRL/MpJ and SJL/J) and to identify epistatic interactions at multiple time points. In this report, we present data showing the identification of same QTLs at each time point that explain $70 \%$ of the variance in $\mathrm{F}_{2}$ mice and that QTL together with epistatic interactions could promote wound healing. 


\section{RESULTS}

\section{Wound Healing in Progenitor Mice (MRL/MP]} and SJL/]) From Day 1 to Day 40 and the Distribution of Hole Size in $\mathrm{F}_{2}$ Mice Population at Day 21

To study the genetic mechanisms of wound healing, two progenitor strains (MRL/MpJ and SJL/J) with extreme phenotype were needed for $\mathrm{F}_{2}$ intercross. Figure 1 shows the comparison of wound healing in MRL/MpJ (fast healer) and SJL/J (slow healer) progenitor strains. MRL/MpJ heals fast and closes the 2-mm hole within 30 days while SJL/J heals $<25 \%$ at the same period of time, indicating that MRL and SJL are good models to study molecular mechanisms of wound healing. Figure 2 shows the distribution of wound healing size at day 21, demonstrating a normal distribution indicating that the ear phenotype is multigene controlled. The distribution also demonstrates that some $\mathrm{F}_{2}$ mice heal faster than MRL/MPJ progenitor (fast healer) and others heal less than SJL/J (slow healer) (shown by arrows). The results show large differences in wound healing between MRL and SJL progenitor mice, and phenotype-dependent $\mathrm{F}_{2}$ distributions demonstrate the inherited nature of the rate of wound healing. As shown in Figure 2 , the $\mathrm{F}_{1}$ have a mean hole size $(0.8 \mathrm{~mm})$ that is intermediate of the progenitor strains with a standard deviation of 0.233 . Therefore, these data are ideal for use in quantitativetrait loci studies to map genes for wound healing.

\section{Use of High-Density Genome-Wide Scan to Identify QTL at Different Timepoints in $633(\mathrm{MRL} \times \mathrm{S}) \mathrm{L})$ $\mathrm{F}_{2}$ Mice}

To increase the power of the study to detect QTL, we used 119 markers and $633 \mathrm{~F}_{2}$ mice. Over 560 microsatellite markers were screened for polymorphisms between MRL/MpJ and SJL/J mice. One hundred and fifty eight markers were informative between the two progenitor strains of mice. After the first round of QTL loci screen, extra markers were added within the QTL regions to increase the accuracy of QTL position. The markers then were chosen depending on their position on the chromosome in an effort to distribute them at about $15 \mathrm{cM}$ or less to generate a complete genome-wide scan.

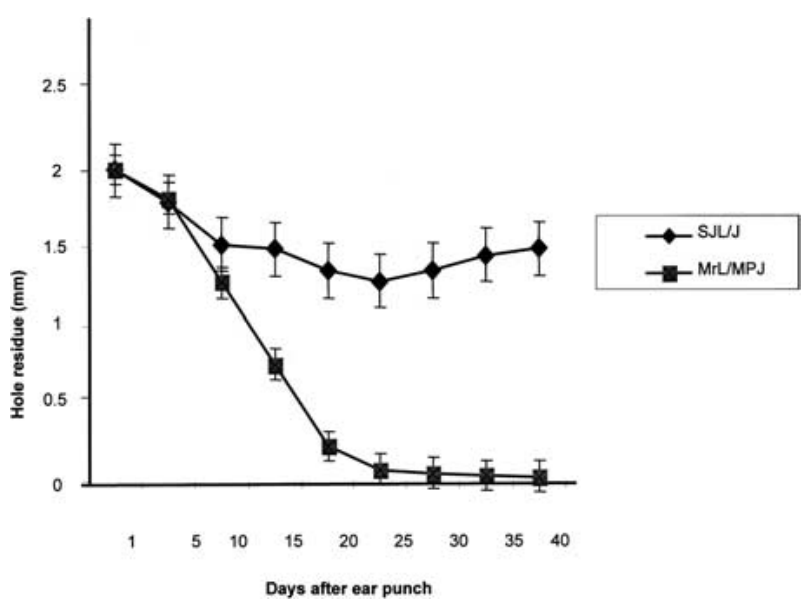

Figure 1 Rates of healing of 2-mm ear hole in MRL (fast healer) and SJL (slow healer) progenitor mice at different timepoints (days 1-40). The $Y$-axis shows the hole residue in millimeters $(\mathrm{mm})$, and the $X$-axis shows the number of days after the ear punch.
F2

Shapiro-Wilk $W=.98281, p<.1759$

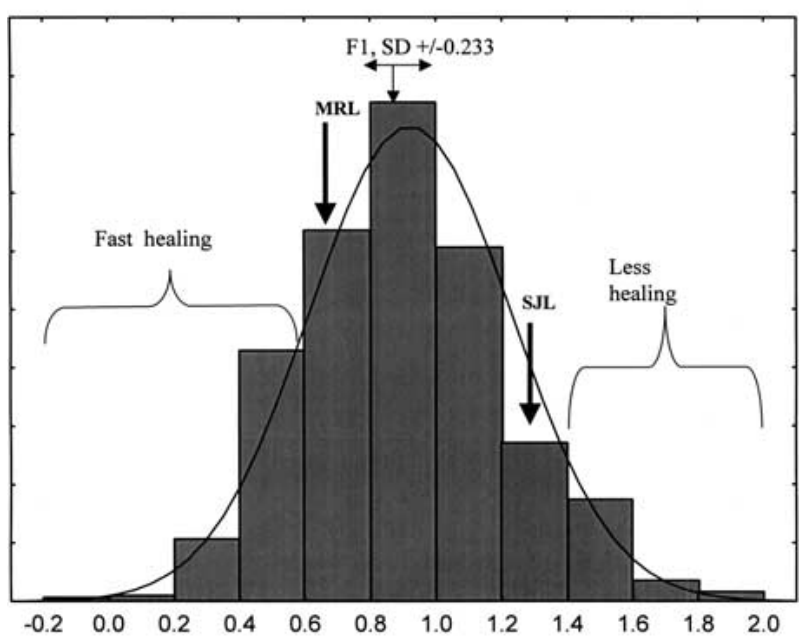

Hole residue $(\mathrm{mm})$

Figure 2 The histogram of frequencies of the hole residue size on day 21 after wounding in $\mathrm{F}_{2}(\mathrm{MRL} / \mathrm{MpJ} \times \mathrm{SJL})$ mice population. Arrows indicate $F_{2}$ that heal better than $\mathrm{MRL} / \mathrm{MpJ}$ and $\mathrm{F}_{2}$ that heal worse than $\mathrm{SJL/J}$ progenitor mice. The $Y$-axis shows the number of observations, and the $X$-axis shows the hole residue in millimeters $(\mathrm{mm})$.

The 119 markers were used to detect QTL involved in wound healing/regeneration in $633(\mathrm{MRL} / \mathrm{MpJ} \times \mathrm{SJL} / \mathrm{J}) \mathrm{F}_{2}$ mice intercross at multiple time points. The order of these markers was as predicted by the available genomic maps (Whitehead Institute, Massachusetts Institute of Technology and Jackson Laboratory, http://www.jax.org).

Multiple timepoints were examined in the present study to determine if different QTL are involved at each stage of wound healing. Table 1 shows that the same QTL were identified at days 15, 21, and 25. By simple linear correlation, significant relationships were noted between hole residue at days 15 and 21 as shown in Figure $4(R=.92$; $P<.0001)$. Similar regression analyses (data not shown) were performed at days 21 and $25(R=.97 ; P<.0001)$ and days 15 and $25(R=.90$; $P<.0001)$, and very strong intraclass correlation of 0.74 , indicating that some of the QTL could be involved in wound healing at all three timepoints. Table 1 and Figure 3 show a total of nine significant QTL (logarithm of the odds [LOD] score $\geq 3.5$ ) and a suggestive QTL on chromosome 13 (LOD score $\geq 2.7$ ). Figure 3 shows histograms of 10 QTL at day 21, which are the same as those at days 15 and 25 . The QTL were identified on chromosomes 1, 3, 4, 6, 7, 9, and 13. Chromosomes 4,7 , and 9 had two QTL each as shown in Figure 3 and Table 1 . The 10 QTL explain $70 \%$ of variance in $\mathrm{F}_{2}$ mice as shown in Table 1 . The 10 QTL are distributed along seven chromosomes with soft tissue heal 3 (Sth3) and Sth4 on chromosome 4, Sth6 and Sth7 on chromosome 7, and Sth8 and Sth9 on chromosome 9. Because one quantitative trait locus is fitted to the model at a time, the estimated effects of the two QTL on the same chromosome may be biased. Figure 5 shows peak loci that exhibited significant/suggestive associations between the genotypic markers and phenotypic values. Out of the 10 QTL, eight MRL homozygote genotypes contributed more in promoting wound healing than SJL homozygote (ex- 
Table 1. Location of Sth QTL as Determined from the $F_{2}$ Intercross

\begin{tabular}{|c|c|c|c|c|c|c|}
\hline \multirow[b]{2}{*}{ QTL } & \multirow{2}{*}{$\begin{array}{l}\text { Microsatelite } \\
\text { marker }\end{array}$} & \multirow[b]{2}{*}{ cM } & \multicolumn{3}{|c|}{ LOD score (\% explained) } & \multirow{2}{*}{$\begin{array}{c}\text { Avg \% } \\
\text { Expl }\end{array}$} \\
\hline & & & Day 15 & Day 21 & Day 25 & \\
\hline Sth1 & D1MIT334 & 49.2 & $6.95(5.8)$ & $6.82(5.6)$ & $7.06(5.8)$ & 6.94 \\
\hline Sth2 & D3MIT217 & 43.7 & $5.86(7.0)$ & $6.18(7.6)$ & $5.38(6.5)$ & 7.0 \\
\hline Sth3 & D4MIT214 & 21.9 & $6.48(5.7)$ & $7.26(6.4)$ & $6.14(5.4)$ & 6.6 \\
\hline Sth4 & D4MIT31 & 50.3 & $5.30(5.5)$ & $6.82(6.2)$ & $6.50(6.0)$ & 6.2 \\
\hline Sth5 & D6MIT261 & 29.5 & $3.60(3.2)$ & $4.50(4.0)$ & $4.11(3.7)$ & 4.07 \\
\hline Sth6* & D7MIT220 & 38.3 & $3.05(2.9)(\mathrm{S})$ & $4.36(4.1)$ & $4.84(4.8)$ & 4.08 \\
\hline Sth7 & D7MIT12 & 62.3 & $3.54(3.1)$ & $3.84(3.6)$ & $4.26(3.9)$ & 3.88 \\
\hline Sth8 & D9MIT207 & 31.7 & $11.99(10.2)$ & $13.95(11.8)$ & $14.18(12.0)$ & 13.54 \\
\hline Sth9 & D9MIT270 & 41.5 & $12.99(10.8)$ & $15.60(13.0)$ & $16.11(13.3)$ & 14.90 \\
\hline Sth10* & D13MIT228 & 45.9 & $2.92(2.5)(S)$ & $3.03(2.6)(S)$ & $2.72(2.4)(S)$ & 2.89 \\
\hline
\end{tabular}

The LOD threshold determined by permutation test is $\geq 3.5$ for significant linkage and 2.7 for suggestive linkage (the same as significant level of $1 \%$ and $5 \%$, respectively) for a chromosome length of $100 \mathrm{cM}$.

${ }^{*}$ QTLs identified previously by McBrearty et al. (1998).

Avg $\% \operatorname{Exp}=$ Average (days 15,21 , and 25 ) percent variance explained $F_{2}$ mice (70\%).

cept for Sth6 QTL in which SJL homozygote contributed more to promote wound healing than MRL homozygote, Fig. 5, bottom). The alleles at four out of the 10 QTL showed a dominant inheritance (Sth1, Sth2, Sth6, and Sth10) while the remaining six QTL demonstrated an additive inheritance. Wound healing may be influenced not only by these QTL but also by epistatic interactions between different loci in the QTL.

\section{Epistatic Interactions Within Different QTL Promote Wound Healing in (MRL $\times$ SJL) $F_{2}$ Mice}

Epistatic interactions could be involved in wound healing at each time point (days 15, 21, and 25). Table 2 shows 17 different epistatic interactions between different loci. A two-way ANOVA model was used to identify interactions, which were significant at $P<0.05$. Five loci had epistatic interactions at day 15 only, 2 loci at day 15 and 21, three loci at days 15, 21, and 25, while three loci were significant at days 21 and 25 , and lastly, four loci were only significant at day 25 . All the significant loci at day 21 also were found either at day 15 or day 25. Day 21 is a transition between fast wound healing and remodeling stages, therefore an overlap of loci interaction is expected. There were unique epistatic interactions at each time point, though some interactions were present at days 15 , 21 , and 25, indicating that some loci are involved at all time points of wound healing tested.

To determine if allelic variation contributes to wound healing at each of the significant loci, a two-sided t-test was performed on the three allelic $(\mathrm{A}, \mathrm{B}, \mathrm{H})$ combinations. The data presented in Figure 6 show two examples of epistatic interactions to illustrate the different effects of allelic combination. Figure $6 \mathrm{~A}$ shows an epistatic interaction between loci on Chrs 6 and 13, represented by markers D6mit291 and D13mit229. It is described as an interaction between the additive effects from Chrs 6 and Chrs 13, leading to better wound healing. Overall, out of the eight possible allelic combinations, allele AA combination significantly promotes wound healing $(P<.03)$. Mice with 'Aa' allele combination healed $57 \%$ of the wound while those carrying ' $\mathrm{Ba}$ ' allele only $46 \%(P<.0005$, indicated by *). Secondly, Figure 6B shows loci interaction between D1Mit334 and D7Mit220 on Chrs 1 and 7. Mice carrying 'Aa' allelic combination generally do not sig- nificantly contribute to better wound as compared to the mice with other eight allelic combinations. $\mathrm{F}_{2}$ mice with allele combination of ' $\mathrm{Ba}^{\prime}$ heal $62 \%$ of the wound as compared to mice with 'Ah' allele combination, which heal only $47 \%(P$ $<.008$, indicated by *).

\section{DISCUSSION}

Wound healing occurs in three stages, inflammatory $(0-2 \mathrm{~d})$, fast wound healing (5-20 d), and remodeling stages (>21 d) (Martin 1997; Singer et al. 1999). In this study, we examined days 15,21 , and 25 with the hypothesis that genes involved in wound healing could be different at each time point. The major findings of these studies were (1) 10 QTL were identified, eight novel and two previously identified by McBrearty et al. (1998), together explain 70\% of the variance in wound healing of $\mathrm{F}_{2} \mathrm{MRL} / \mathrm{SJL}$ intercross, and surprisingly, all the QTL were identical at each time point, and (2) some epistatic interactions were unique for each wound-healing stage, while others were common at all time points. These findings will be discussed sequentially.

\section{The Same QTL Were Identified at Each Timepoint and Together Explained $70 \%$ of Variance in Wound Healing in the (MRL/SJL) $F_{2}$ Mice}

To identify QTL that may carry genes that are involved in fast wound healing, MRL-MPJ and SJL/J mice were selected, as they have extreme ear healing capacity. The phenotype shows a normal distribution in $\mathrm{F}_{2}$ mice intercross (MRL-MPJ $\times \mathrm{SJL} /$ $\mathrm{J})$, a distribution that indicates that the genes regulating fast wound healing have additive effects and no major gene with dominant inheritance exists in the segregating population, features consistent with polygenic inheritance.

We used $(\mathrm{MRL} \times \mathrm{SJL} / \mathrm{J}) \mathrm{F}_{2}$ cross to identify $10 \mathrm{QTL}$, eight were novel and two were identified previously by McBrearty et al. (1998). Because of the different genetic origin between progenitor strains (MRL and SJL/J), our study identified eight QTL that could not be identified using MRL $\times$ C57BL/6 combination (McBrearty et al. 1998). Our study used the same fast healer, MRL, as in McBrearty et al. (1998), but a different slow healer, SJL/J. The QTL on chromosome 7 and a suggestive QTL 

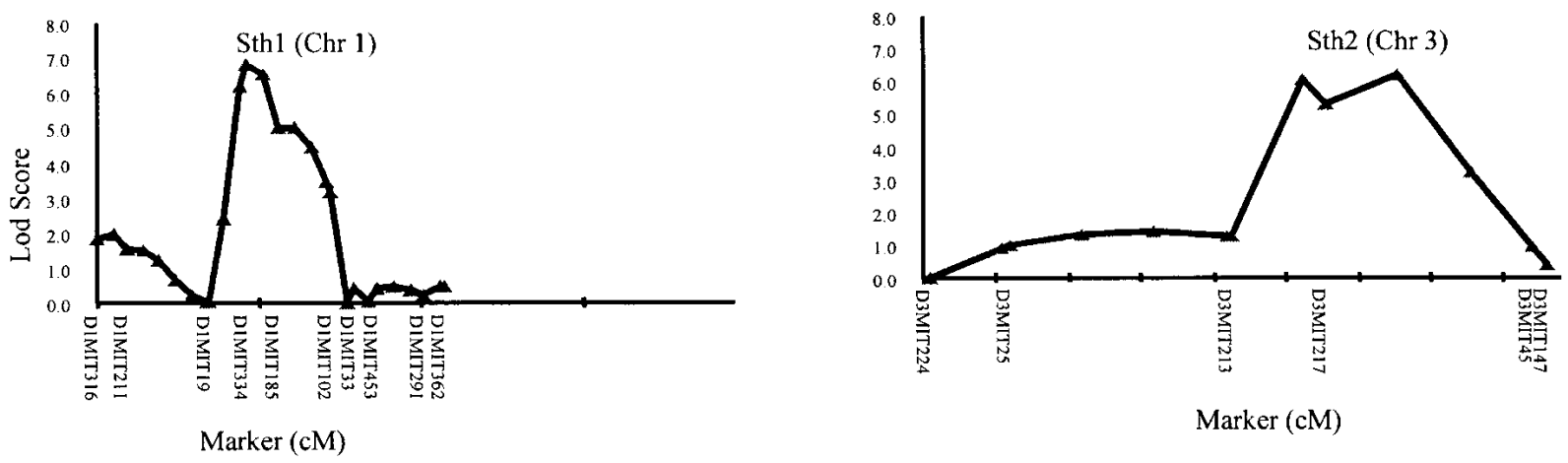

Marker (cM)
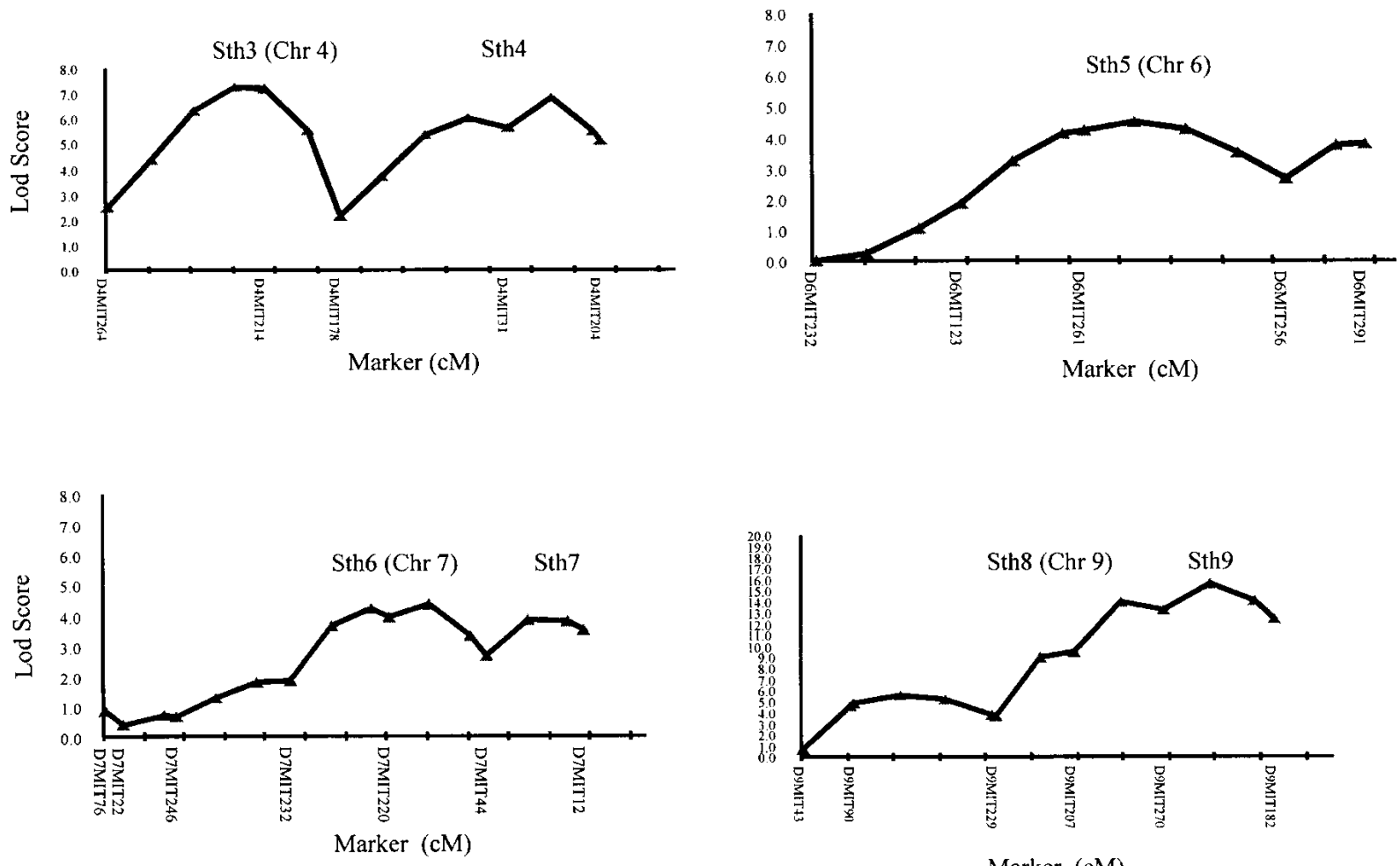

Marker (cM)

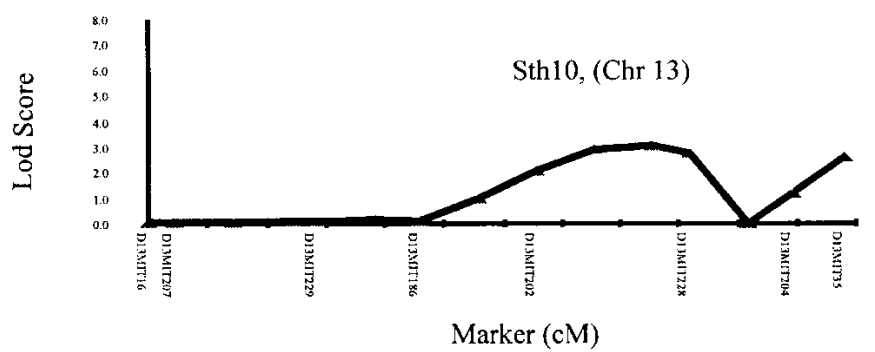

Figure 3 Interval mapping at day 21, showing significant quantitative trait loci (QTL) (1,3,4,6,7, and 9) and a suggestive QTL on chromosome 13. The logarithm of the odds (LOD) score is on the $Y$-axis and relative location of marker name and distribution in centiMorgans (cM) on the $X$-axis. The QTL are labeled as soft tissue heal (Sth) at each peak.

on chromosome 13 were identified also by McBrearty et al. (1998) using MRL $\times$ C57BL/6 strain combination. To our surprise, one of the two QTL on chromosome 7 (D7Mit220) is contributed by SJL/J, a poor healer, indicating that even poor healers that do not express the trait are important in the promotion of wound healing (Frankel 1995; McBrearty et al. 


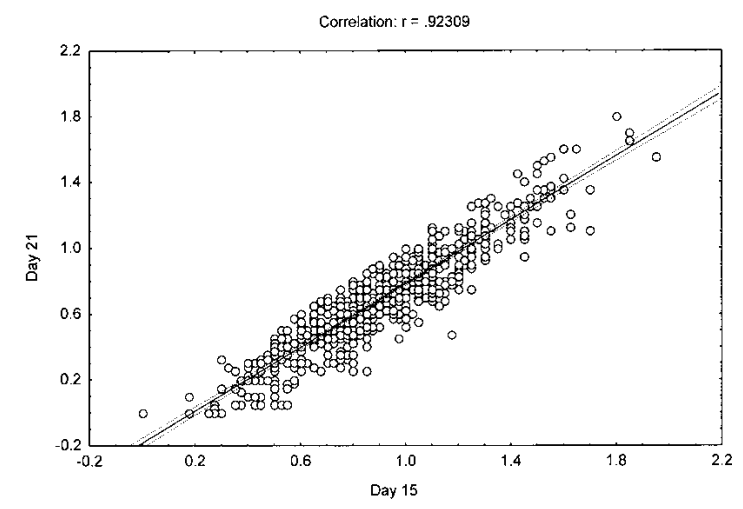

Figure 4 Ear hole size $(\mathrm{mm})$ at day 15 was regressed against ear hole size $(\mathrm{mm})$ at day 21 . The correlation coefficient and the significance level are indicated. All the other comparisons (day 15 against day 25 and day 21 against day 25) showed the same high significance level.

1998). These findings show that the major contributor to wound healing is MRL, as it is the common strain between this study and the McBrearty et al. (1998) study. The 10 QTL explained $70 \%$ of variance in $\mathrm{F}_{2}$ mice. As explained in the results section on the percentage explained by variance, the QTL analysis program fitted only a single model each time so there could have been an overestimate on the chromosomes that had more than one quantitative trait locus. A very conservative value may be between $50 \%$ and $70 \%$. To our knowledge, there is no other mouse QTL study that has explained such a high percentage of variance for any phenotype. The reasons could be partly because of high marker density ge-
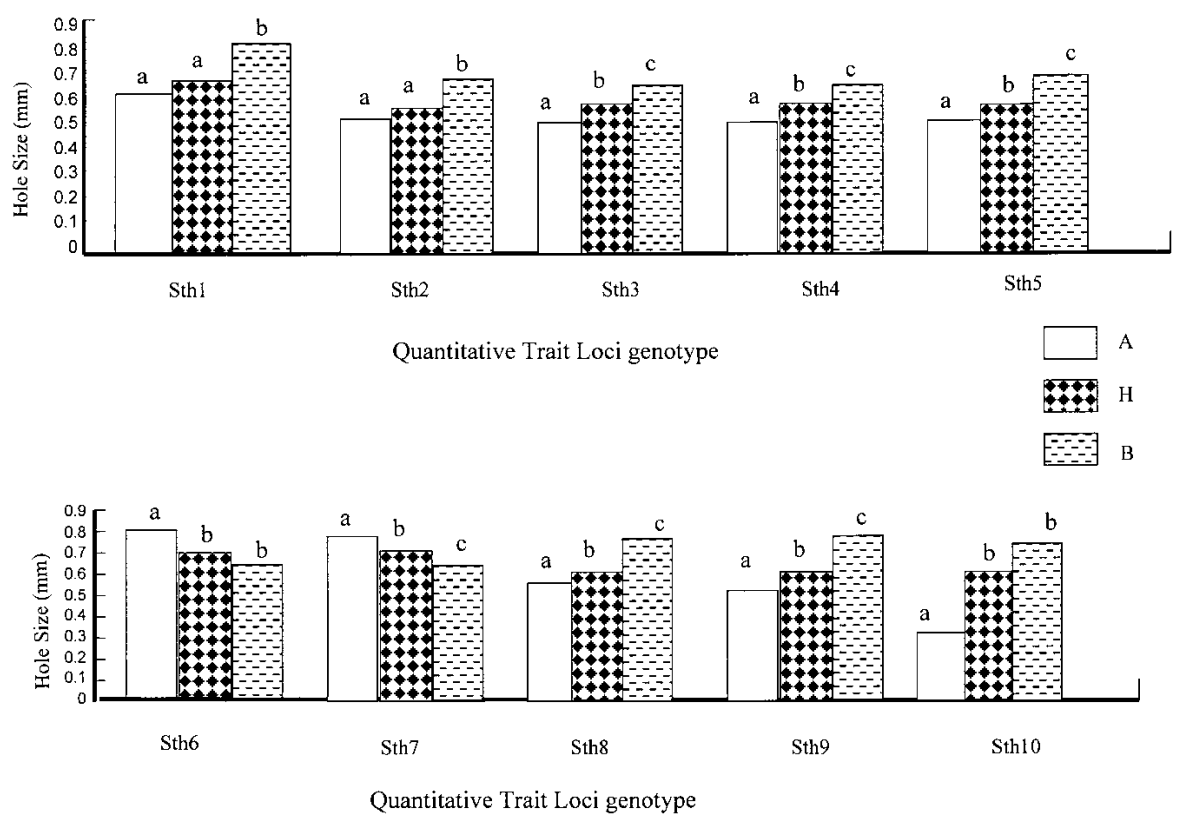

Figure 5 The effects of genotype on hole size in $\mathrm{mm}$. The genotypes were derived from the markers near the quantitative trait loci (QTL) peaks. The capital letters A and B represent homozygote genotype for $\mathrm{Mrl} / \mathrm{MPJ}$ and SJL/J mice, respectively, and $\mathrm{H}$ represents heterozygotes genotype. The lower case letters on the top of bars indicate the level of difference in phenotypic value between genotypes. If the two bars share the same letter, the value between the two genotypes will not be statistically significant, but if different, then they are statistically different at $P<.05$.
Q9 $\mathrm{H}$

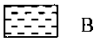

nome-wide scan, which increased the QTL detection power (Moore and Nagle 2000). be involved at each stage of wound healing/regen tion (Martin 1997; Singer et al. 1999). Surprisingly, the same ifified at each time point, with very high phe, correlation between days 15,21 , and 25 , and intraerion, suggesting that some genes could be involved in the three time points tested. There is evidence that some genes are consistently up-regulated at all stages of (Iyer et al. 1999; Li l. 2001a,c). An example of these genes are insulin-like t IGFBP-1), IGF-1 receptor, transforming growth facgrowth factor receptor $2(F G F R 2)$, vascular endothelial growth factor $(V E G F)$, and bone morphogenetic protein 4(BMP4) (Li et al. 2001c). This indicates that growth factors are involved in all stages of wound healing, which solidifies our suggestion that some genes participate at the three time-

Epistatic Interactions Could be Important in the Promotion of Wound Healing in (MRL-MPJ x SJL) $\mathrm{F}_{2}$ Mice Intercross

In this study, we hypothesized that lower LOD scores $(<2.7)$ will show significant interactions. A two-way ANOVA test del was used in genome wide scan to identify 17 epistatic interactions. Markers with LOD scores $\geq 2.7$ and $<3.5$ identified four interactions, while those with $\leq 2.0<2.7$ LOD score identified three interactions and $\geq 3.5$ identified 10 interactions. We only analyzed loci with $\geq 2.0$ LOD score from all the chromosomes, therefore, there is a possibility that interactions of markers with $<2.0$ LOD score were missed. Indeed, we were surprised by the fact that some loci interacted at all the three time points, which included Sth 4 on chromosome 4, Sth5 on chromosome 6, Sth8 on chromosome 9, and Sth10 on chromosome 13. This again shows that some genes are involved at all the three time points examined in this study. Therefore, epistatic interactions together with individual loci may constitute a genetic repertoire to promote wound healing.

We detected 17 epistatic interactions that could play a crucial role in wound healing. This study provides a wealth of information that should lead to more detailed understanding of wound healing. One unique feature of this study is the use of progenitor strains that have extreme phenotypes (SJL healed only $20 \%$ vs. $100 \%$ in MRL), therefore, the QTL in this study are 
Table 2. Loci that Produce Genetically Significant Interactions by a Two-Way ANOVA Analysis

\begin{tabular}{|c|c|c|c|c|c|c|c|c|}
\hline \multicolumn{3}{|c|}{ Day 15} & \multicolumn{3}{|c|}{ Day 21} & \multicolumn{3}{|c|}{ Day 25} \\
\hline Locus 1 & Locus 2 & $P$-value & Locus 1 & Locus 2 & $P$-value & Locus 1 & Locus 2 & $P$-value \\
\hline D1MIT334 & D6MIT232 & 0.04 & & & & & & \\
\hline D1MIT185 & D3MIT217 & 0.04 & & & & & & \\
\hline D4MIT204 & D13MIT229 & 0.03 & & & & & & \\
\hline D6MIT261 & D9MIT90 & 0.026 & & & & & & \\
\hline D9MIT182 & D6MIT232 & 0.024 & & & & & & \\
\hline D1MIT334 & D7MIT220* & 0.02 & D1MIT334 & D7MIT220* & 0.022 & & & \\
\hline D4MIT204 & D9MIT229 & 0.02 & D4MIT204 & D9MIT229 & 0.021 & & & \\
\hline D4MIT204 & D9MIT43 & 0.0037 & D4MIT204 & D9MIT43 & 0.0065 & D4MIT204 & D9MIT43 & 0.001 \\
\hline D6MIT261 & D9MIT43 & 0.005 & D6MIT261 & D9MIT43 & 0.049 & D6MIT261 & D9MIT43 & 0.017 \\
\hline \multirow[t]{8}{*}{ D6MIT291 } & D13MIT229 & 0.0093 & D6MIT291 & D13MIT229 & 0.024 & D6MIT291 & D13MIT229 & 0.014 \\
\hline & & & D4MIT204 & D9MIT90 & 0.026 & D4MIT204 & D9MIT90 & 0.01 \\
\hline & & & D9MIT229 & D13MIT228 & 0.041 & D9MIT229 & D13MIT228 & 0.018 \\
\hline & & & D9MIT229 & D13MIT35 & 0.025 & D9MIT229 & D13MIT35 & 0.017 \\
\hline & & & & & & D4MIT214 & D9MIT90 & 0.048 \\
\hline & & & & & & D4MIT214 & D9MIT43 & 0.026 \\
\hline & & & & & & D4MIT31 & D9MIT90 & 0.048 \\
\hline & & & & & & D4MIT31 & D9MIT43 & 0.025 \\
\hline
\end{tabular}

expected to yield key wound-healing genes.

\section{METHODS}

\section{Mice}

The progenitor strains of MRL/MPJ females and SJL/J males were obtained from Jackson Laboratory. $F_{1}$ from MRL/MPJ and $\mathrm{SJL} / \mathrm{J}$ were crossed to get $\mathrm{F}_{2}$ population. These inbred strains of mice were selected from our earlier study of 20 different strains. The results indicated that MRL/MpJ completely heals and SJL/J heals $<25 \%$ (Li et al. 2001b). Twenty, fourweek-old female mice for MRL/MPJ and $10 \mathrm{SJL} / \mathrm{J}$ male mice were housed at the Animal Research Facility, J.L. Pettis Veterans Administration Medical Center, under the standard condition of $14 \mathrm{~h}$ light, $10 \mathrm{~h}$ darkness, ambient temperature of $20^{\circ} \mathrm{C}$, and relative humidity of $30 \%-60 \%$. All $\mathrm{F}_{1}$ and $\mathrm{F}_{2}$ mice $(\mathrm{MRL} / \mathrm{MPJ} \times \mathrm{SJL} / \mathrm{J})$, crosses were bred at the Animal Research Facility. The experimental protocols were in compliance with the animal welfare regulation and approved by the J.L. Pettis Veterans Adminstration Medical Center.

\section{Ear Punch and Measurement}

Six hundred and thirty-three $\mathrm{F}_{2}$ female mice $(\mathrm{MRL} / \mathrm{MpJ} \times$ $\mathrm{SJL} / \mathrm{J}$ ) were generated to conduct the study. The 3-week-old $\mathrm{F}_{2}$ animals had a 2-mm through-and-through hole in diameter made in the lower cartilaginous part of each ear using a metal ear punch (Fisher Scientific). The hole closure was measured using a $7 \times$ magnifier at days 15,21 , and 25 after ear punch. Each hole was measured twice (horizontal and vertical measurement) from the back of the ear (less hair at the back), and the average value for each animal was calculated from four measurements of two ears and was used in the data analysis. The precision of hole measurement, determined by repeatedly measuring the same hole 10 times, was $2.4 \%$ when the average size was $1.4 \mathrm{~mm}$ in diameter and $4.6 \%$ when the average size was $0.96 \mathrm{~mm}$ in diameter (Li et al. 2001b).

\section{Genetic Analysis}

The $(\mathrm{MRL} / \mathrm{MpJ} \times \mathrm{SJL} / \mathrm{J}) \mathrm{F}_{2}$ population was killed at the age of $7 \mathrm{wk}$. Genomic DNA was prepared from the liver of each $\mathrm{F}_{2}$ animal population using a Wizard Genomic DNA kit (Promega), according to the manufacturer's instructions. DNA
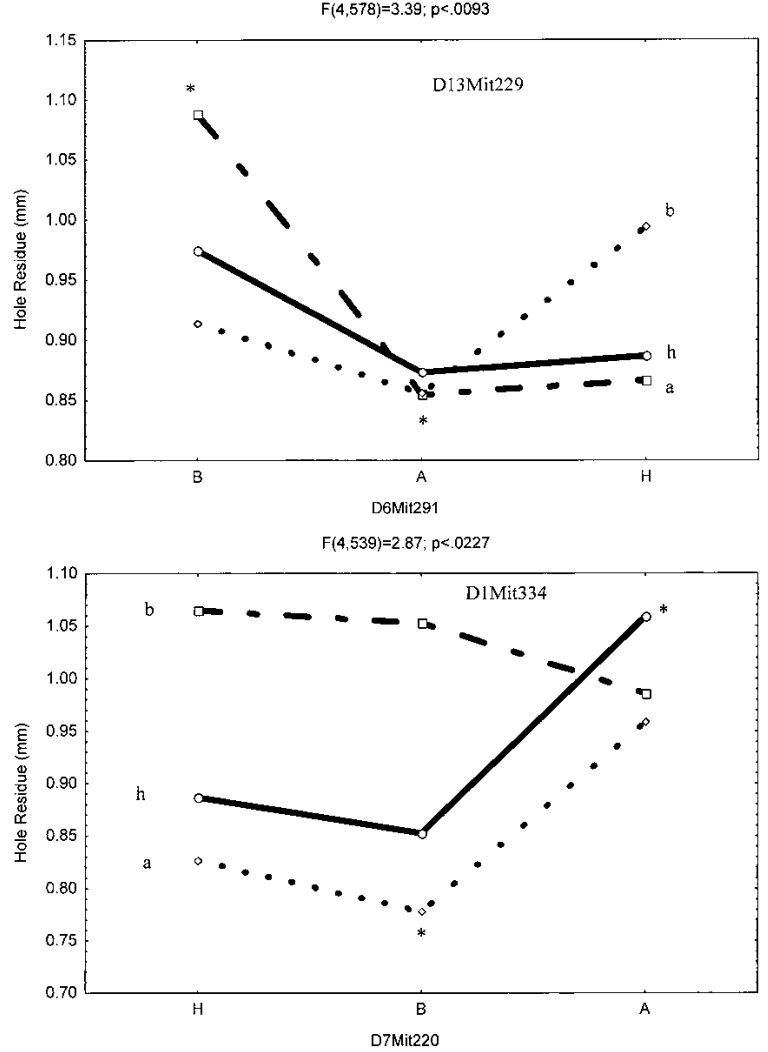

Figure 6 The interactive effects of the QTLs, with three alleles, A (MRL), B (SJL) and $\mathrm{H}$ (heterozygotes). (A) Shows epistatic interaction between loci D6Mit291 and D13Mit229. The $Y$-axis (left side) shows hole residue in millimeters $(\mathrm{mm}), Y$-axis right side loci D13Mit229 (a, $\mathrm{h}$, and $\mathrm{b}$ ) and the $X$-axis shows loci D6Mit291 (B, H, and A). The * means significantly different from the two extreme allelic combinations ( $\mathrm{Aa}$ and $\mathrm{Ba}$ ). (B) Shows epistatic interaction between loci D1Mit334 and D7Mit220. The Y-axis (left side) shows hole residue in millimeters (mm), $Y$-axis right side loci D1Mit334 (a, h, and b) and the $X$-axis shows loci D7Mit220 (H, B, and A). The * means significantly different from the two extreme allelic combinations ( $\mathrm{Ba}$ and $\mathrm{Ah}$ alleles). 
was stored at $-35^{\circ} \mathrm{C}$ for later use. DNA was diluted 2:40 in 96 well plates before use for genotyping. Polymerase chain reaction (PCR) primers were purchased from Research Genetics to perform a genome-wide scan of the $\mathrm{F}_{2}$ mice population. Amplification was performed using Promega reagents (Promega). PCR cycling conditions included $4 \mathrm{~min}$ at $94^{\circ} \mathrm{C} \times 1 ; 45 \mathrm{sec}$ at $94^{\circ} \mathrm{C} ; 30 \mathrm{sec}$ at $52^{\circ} \mathrm{C} \times 14 ; 45 \mathrm{sec}$ at $94^{\circ} \mathrm{C}, 30 \mathrm{sec}$ at $50^{\circ} \mathrm{C}, 1$ $\min$ at $72^{\circ} \mathrm{C} \times 32 ; 7 \mathrm{~min}$ at $72^{\circ} \mathrm{C} \times 1$. PCR products were resolved on $6 \%$ polyacrylamide gels (19:1 acrylamide: bis), stained with ethidium bromide, and visualized by ChemiImager 4400 Low Light Imaging System (Alpha Innotech Corporation). Pictures of the gels were taken and alleles recorded. Alleles derived from the MRL/MpJ parent were designated $\mathrm{A}$, $\mathrm{SJL} / \mathrm{J}$ derived alleles designated $\mathrm{B}$, and $\mathrm{H}$ for heterozygotes, in data analysis.

\section{Statistics}

Genotype data was analyzed using a MAPQTL (4.0) program (CPRO-DLO). MAPQTLS interval mapping was utilized for quantitative trait loci mapping, and the LOD score significance thresholds were calculated using MAPQTL permutation test. A significant LOD score is $\geq 3.5$. The significant LOD score for our data is the same as the values proposed by Van Ooijen (1999). A two-way ANOVA genome-wide scan was performed to identify epistatic interactions for markers with $\geq$ 2.0 LOD scores.

\section{ACKNOWLEDGMENTS}

Assistance Award no. DAMD17-99-1-9571 supported this work. The US Army Medical Research Acquisition Activity is the awarding and administering acquisition office. The information contained in this paper does not necessarily reflect the position or policy of the Government and no official endorsement should be inferred. The authors thank the J.L. Pettis Veterans Administration Medical Center staff for their support. The authors also thank Melanie Hamilton-Ulland for excellent technical support.

The publication costs of this article were defrayed in part by payment of page charges. This article must therefore be hereby marked "advertisement" in accordance with 18 USC section 1734 solely to indicate this fact.

\section{REFERENCES}

Beck, J.A., Lloyd, S., Hafezparast, M., Lennon-Pierce, M., Eppig, J.T., Festing, M.F., and Fisher, E.M. 2000. Genealogies of mouse inbred strains. Nat. Genet. 24: 23-25.

Buchman, V.L., Sporn, M., Davies, A.M. 1994. Role of transforming growth factor-beta isoforms in regulating the expression of nerve growth factor and neurotrophin-3 mRNA levels in embryonic cutaneous cells at different stages of development. Development 120: $1621-1629$.

Carlson, M.R., Bryant, S.V., and Gardiner, D.M. 1998. Expression of Msx-2 during development, regeneration and wound healing in axolotl limbs. J. Exp. Zool. 282: 715-723.

Chen, E.A., Zhao, L., Bamat, M., Von Borstel, R., and Mustoe, T. 1999. Acceleration of wound healing with topically applied deoxyribonucleosides. Arch. Surg. 134: 520-525.

Clark, L.D., Clark, R.K., Heber-Katz, E. 1998. A new murine model for mammalian wound repair and regeneration. Clin. Immunol. Immunopathol. 88: 35-45.

Frankel, W. 1995. Taking stock of complex trait genetics in mice. Trends Genet. 11: 471-477.

Goss, R.J. 1992. The evolution of regeneration. Adaptive or inherent? I. Theor. Biol. 159: 241-260.

Heber-Katz, E. 1999. The regenerating mouse ear. Semin. Cell Develop. Biol. 10: 415-419.

Iyer, V.R., Eisen, M.B., Ross, D.T., Schuler, G., Moore, T., Lee, J.C., Trent, J.M., Staudt, L.M., Hudson, J. Jr., Boguski, M.S., et al. 1999. The transcriptional program in the response of human fibroblast to serum. Science 283: 83-87.

Li, X., Mohan, S., Gu, W., and Baylink, D.J. 2001a. Analysis of gene expression in wound repair/regeneration process. Mamm. Genome 12: $52-59$.

Li, X., Gu, W., Masinde, G., Hamilton-Ulland, M., Xu, S., Mohan, S., and Baylink, D.J. 2001b. Genetic control of the rate of wound healing in mice. J. Hered. 86: 1-7.

Li, X., Gu, W., Masinde, G., Covarrubias, M., Mohan, S., and Baylink, D.J. 2001c Temporal analysis of gene expression by microarray during wound healing, Wounds, in press.

Lynch, S.E., Colvin, B.B., Antoniades, H.N. 1989. Growth factors in wound healing. Single and synergistic effectiveness of partial thickness porcine skin wounds. J. Clin. Invest. 84: 640-646.

Kunimoto, B.T. 1999. Growth factors in wound healing: The next great innovation? Ostomy/Wound Management 45: 56-64.

Martin, P. 1997. Wound healing-aiming for perfect skin regeneration. Science 276: 75-81.

McBrearty, B.A., Clark, L.D., Zhang, X.M., Blankenhorn, E.P., Heber-Katz, E. 1998. Genetic analysis of a mammalian wound-healing trait. Proc. Natl. Acad. Sci. 95: 11792-11797.

Moore, K.J. and Nagle, L.D. 2000. Complex trait analysis in the mouse: The strengths, the limitations and the promise yet to come. Annu. Rev. Genet. 34: 653-686.

Reginelli, A.D., Wang, Y.-Q., Sassoon, D., and Muneoka, K. 1995. Development 121: 1065-1076.

Rothe, M. and Falanga, V. 1992. Growth factors and wound healing. Clin. Dermatol. 9: 553-559.

Satcher, D. 2000. Injury: An overlooked global health concern. Department of Health and Human Services. Public use data tape: 1993-detail mortality file. Hyattsville, MD: National Center for Health Statistics, 1995. JAMA 284: 950.

Shan, M., Foreman, D.M., Ferguson, M.W.J. 1995. Neutralization of TGF- $\beta_{1}$ and TGF $-\beta_{2}$ or exogenous addition of TGF- $\beta_{3}$ to cutaneous rat wounds reduces scarring. J. Cell Sci. 108: $985-1002$.

Singer, A.J. and Clark, R.A.F. 1999. Cutaneous wound healing. N. Engl. J. Med. 341: 738-746.

Stocum, D.L. 1996. Tissue restoration: Approaches and prospects. Wound Rep. Reg. 4: 3-15.

Terkelsen, L.H., Eskild-Jensen, A., Kjeldsen, H., Barker, J.H., Hjortdal, V.E. 2000. Topical application of cod liver oil ointment accelerates wound healing: An experimental study in wounds in the ears of hairless mice. Scand. J. Plast. Reconstr. Surg. Hand Surg. 34: $15-20$.

Trengove, N.J., Bielefeldt-Ohmann., H., Stacey, M.C. 2000. Mitogenic activity and cytokine levels in non healing and healing chronic leg ulcers. Wound Rep. Reg. 8: 13-25.

Van Ooijen, J.W. and Maliepaard, C. 1996. MapQTLs (tm) version 4.0: Software for the calculation of QTLS positions on the genetic maps. CPRO-DLO, Wageningen, The Netherlands.

Van Ooijen, J.W. 1999. LOD significance thresholds for QTLS analysis in experimental populations of diploid species. Heredity 83: $613-624$.

Received July 2, 2001; accepted in revised form September 19, 2001. 


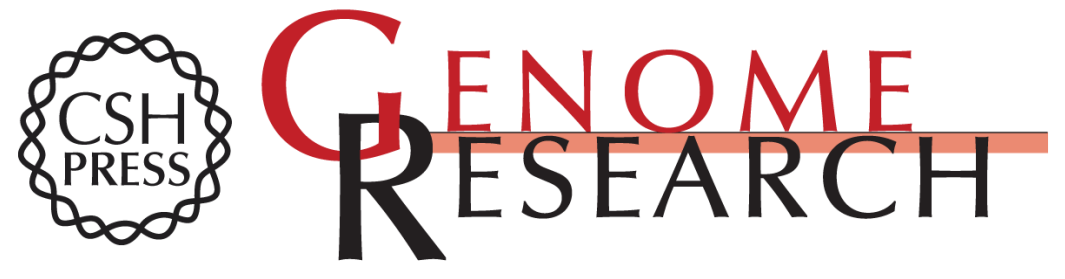

\section{Identification of Wound Healing/Regeneration Quantitative Trait Loci (QTL) at Multiple Time Points that Explain Seventy Percent of Variance in (MRL/MpJ and SJL/J) Mice $F_{2}$ Population}

Godfred L. Masinde, Xinmin Li, Weikuan Gu, et al.

Genome Res. 2001 11: 2027-2033

Access the most recent version at doi:10.1101/gr.203701

References This article cites 22 articles, 6 of which can be accessed free at:

http://genome.cshlp.org/content/11/12/2027.full.html\#ref-list-1

License

Email Alerting Receive free email alerts when new articles cite this article - sign up in the box at the Service top right corner of the article or click here.

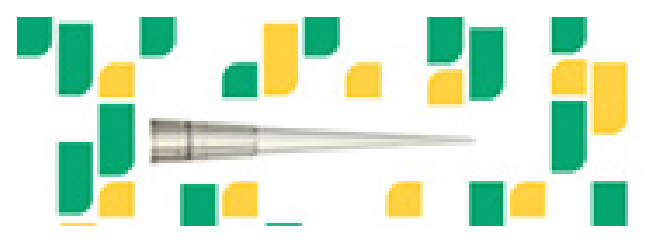

Focused on your science.

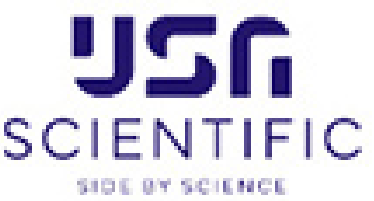

To subscribe to Genome Research go to:

https://genome.cshlp.org/subscriptions 